Published in final edited form as:

J Nurse Pract. 2015 May ; 11(5): 551-559. doi:10.1016/j.nurpra.2015.02.004.

\title{
An Update on Pulmonary Arterial Hypertension
}

\author{
Joanna Wapner, MSN, RN and \\ University of Pennsylvania, 2101 Market Street Unit 804, Philadelphia PA 19103 \\ Lea Ann Matura, PhD, RN [Assistant Professor] \\ University of Pennsylvania, School of Nursing, Claire M. Fagin Hall, 418 Curie Blvd., Room 322, \\ Philadelphia, Pennsylvania 19104-4217 USA
}

\begin{abstract}
Pulmonary arterial hypertension (PAH) is a progressive disease that ultimately leads to right heart failure and death. PAH is defined as a mean pulmonary arterial pressure $225 \mathrm{~mm} \mathrm{Hg}$ with a pulmonary capillary wedge pressure $\leq 15 \mathrm{~mm} \mathrm{Hg}$ at rest. The diagnosis of PAH is one of exclusion; diagnostics include an extensive history, serology, chest radiograph, pulmonary function tests, ventilation/perfusion scan, transthoracic echocardiogram, and right heart catheterization. Treatment and care of patients with PAH can be complex. Therefore, the nurse practitioner is an integral member of the healthcare team caring for PAH patients, helping to ensure seamless care and support.
\end{abstract}

\section{Keywords}

pulmonary arterial hypertension; pathophysiology; diagnosis; treatment

Pulmonary arterial hypertension (PAH) is a progressive disease that ultimately leads to right heart failure and death. It is hemodynamically defined as a mean pulmonary arterial pressure (mPAP) $\geq 25 \mathrm{~mm} \mathrm{Hg}$ with a pulmonary capillary wedge pressure (PCWP) $\leq 15 \mathrm{~mm} \mathrm{Hg}$ at rest resulting in increased pulmonary vascular resistance. ${ }^{1} \mathrm{PAH}$ is predominantly found in women $(80 \%)$ with the mean age of diagnosis of 53 years. ${ }^{1}$ Patients with PAH may initially report dyspnea especially on exertion along with fatigue. These symptoms can be severe ${ }^{2}$ impairing their ability to function and their health-related quality of life (HRQOL). ${ }^{2}$ Symptoms continue to worsen until patients are diagnosed and therapies are initiated. Diagnosis may be delayed due to the symptoms mimicking other cardiopulmonary disease resulting in worsening right ventricular modeling and increasing mortality. ${ }^{3}$ The purpose of this review is to provide an overview and update on the pathophysiology, classification, diagnosis, and treatment of PAH.

(C) 2015 Published by Elsevier Inc.

jowapner@gmail.com 215-850-2627. Corresponding author: Lea Ann Matura, PhD, RN, Assistant Professor, University of Pennsylvania, School of Nursing, Claire M. Fagin Hall, 418 Curie Blvd., Room 322, Philadelphia, Pennsylvania 19104-4217 USA, tel: 1 (215) 746-8819, matura@nursing.upenn.edu.

Publisher's Disclaimer: This is a PDF file of an unedited manuscript that has been accepted for publication. As a service to our customers we are providing this early version of the manuscript. The manuscript will undergo copyediting, typesetting, and review of the resulting proof before it is published in its final citable form. Please note that during the production process errors may be discovered which could affect the content, and all legal disclaimers that apply to the journal pertain. 


\section{Epidemiology and Classification of Pulmonary Hypertension}

Pulmonary hypertension $(\mathrm{PH})$ is an umbrella term that contains several groups. ${ }^{1}$

Historically, PH was classified into two categories: (1) primary pulmonary hypertension and (2) secondary PH, based on the presence of identified risk factors. During the Second World Symposium on PH in 1998, a clinical classification was developed to categorize forms of PH sharing similar pathological findings, hemodynamic characteristics, and treatment management strategies. Five PH etiology groups were identified: pulmonary arterial hypertension (PAH; Group 1), PH due to left sided heart disease (Group 2), PH due to lung diseases and/or hypoxia (Group 3), chronic thromboembolic pulmonary hypertension (CTEPH; Group 4), and PH with unclear multifactorial mechanisms (Group 5). ${ }^{4}$ In 2013, a symposium was convened to determine if any changes were needed to the current $\mathrm{PH}$ classifications. Consensus determined to maintain most of the previous classifications with some changes in Group 1 (Table 1). ${ }^{1}$

The Registry to Evaluate Early And Long-term pulmonary hypertension disease management (REVEAL Registry ${ }^{\mathrm{TM}}$ ) was a US-based registry, multicenter observational study to assess the clinical course and disease management of patients with PAH. Enrollment included 3,515 patients with PAH who were enrolled between 2006-2009 in order to establish updated characteristics of patients with PAH and to improve diagnosis, treatment and management. ${ }^{5}$ Estimated incidence and prevalence are 2.0 and 10.6 cases per million. ${ }^{6}$ REVEAL data show there is a 4.1:1 female-to-male ratio among patients with idiopathic pulmonary arterial hypertension (IPAH) and a 3.8:1 ratio among those patients with associated PAH (APAH) (Table 1).

Idiopathic PAH is diagnosed in approximately $50 \%$ of all patients with PAH. In addition there are heritable forms of PAH which include mutations: bone morphogenetic protein receptor type II (BMPR2), activin receptor like kinase 1 (ALK-I), endoglin; and (CAV I) (Table 1). Disorders associated with PAH include connective tissue disease, HIV, portal hypertension, congenital heart disease and Schistosomiasis. Toxins and drugs have been implicated in the PAH etiology. Definitive causes include anroxigens (aminorex, fenfluramine, dexfenfluramine, benfluorex) along with toxic rapeseed oil. Selective serotonin reuptake inhibitors (SSRIs) are considered a risk factor for the development of persistent pulmonary hypertension in the newborn (PPHN) in pregnant women exposed to SSRIs, especially after 20 weeks of gestation. Other likely causes of PAH include amphetamines, methamphetamines and dasatinib which is a tyrosine kinase inhibitor used for cancer treatment. Other possible causes include cocaine, St. John's wort, Interferon a and $\beta$ and other chemotherapeutic drugs. Although PAH is more prevalent in women oral contraceptives and estrogen are unlikely causes of PAH. ${ }^{1}$

\section{Pathophysiology}

PAH results from restricted blood flow through the pulmonary arterial circulation that leads to increases in pulmonary vascular resistance (PVR) and ultimately right heart failure. PAH is characterized by a variety of arterial abnormalities including intimal hyperplasia, medial hypertrophy, adventitial proliferation, thrombosis in situ, inflammation, and plexiform 
arteriopathy in the pulmonary arterioles. ${ }^{4}$ After the initial insult triggering the onset of PAH remodeling of the pulmonary vasculature begins. There is an increase in pulmonary pressures and PVR. The intravascular lumen diameter decreases due to proliferation of cells in the pulmonary artery smooth muscle cells. Reduced apoptosis or programmed cell death is present. Endothelial dysfunction causes changes in endothelial production and a decreased production of prostacyclin causing vasoconstriction. ${ }^{7}$ Endothelin-1 is increased and causes vasoconstriction and platelet aggregation. There is a decrease in nitric oxide and prostacyclin production in $\mathrm{PAH}$ resulting in vasoconstriction. ${ }^{8}$

Activation of the neurohormonal system including the sympathetic nervous system and the renin-angiotensin-aldosterone system causes vasoconstriction and sodium retention. As pulmonary pressures and vascular resistance continues there is an increase in right ventricular afterload resulting in a decrease in stroke volume and right ventricular ejection fraction. Because the right ventricle myocardium is thinner than the left ventricular wall an increase in pressure causes myocardial oxygen demand and right ventricular hypertrophy. The right ventricle begins to dilate and fail resulting in increased fluid retention.

\section{Diagnosis of PAH Clinical Manifestations}

The evaluation process of a patient with suspected PAH requires a series of diagnostic tests intended to confirm the diagnosis and evaluate the functional status and hemodynamic impairment. ${ }^{5}$ The diagnosis of PAH is one of exclusion. Symptoms such as breathlessness, fatigue, weakness, angina, syncope and abdominal distension mimic other cardiopulmonary diseases. The symptomology along with the lack of awareness of PAH may significantly prolong the time from initial symptom onset to diagnosis. ${ }^{9}$ Furthermore, some symptoms may be derived from the patient's associated disease causing PAH such as Raynaud's phenomenon (numb, painful hands or feet with cold and stress) commonly reported by patients with limited systemic lupus erythematosus. While PAH is considered a rare disease, there may actually be an under diagnosis or misdiagnosis for a period of time because symptoms (e.g. fatigue and dyspnea) are similar to other disorders. Patients with PAH have described their trajectory from initial symptoms to diagnosis that have been categorized into three categories: making sense of symptoms; process of elimination; and being diagnosed with PAH. Early in their disease patients tried to continue their usual activities even with burdensome symptoms such as dyspnea until they had to seek medical care. Diagnosis was made over an extended period of time with misdiagnoses common. ${ }^{9}$

Patients are assigned a New York Heart Association (NYHA) functional class group based on symptoms with activity. ${ }^{10}$ NYHA functional class I are those patients who do not have symptoms such as fatigue and dyspnea with ordinary physical activity. NYHA functional class II are those patients who have symptoms with ordinary activity that slightly limits their activity levels. NYHA functional III are those who symptoms with less than usual activity and marked limitation in their activity level whereas NHYA functional class IV are those patients who are symptomatic even at rest. 
On physical exam the signs of PAH include left parasternal lift, an accentuated pulmonary component of the second heart sound, a pansystolic murmur of tricuspid regurgitation and a diastolic murmur of pulmonary insufficiency. Jugular venous distention, hepatomegaly, peripheral edema, ascites, and cool extremities represent more advanced disease.

\section{Diagnostics}

In initial workup an electrocardiogram (ECG) should be performed to assess for right axis deviation and right ventricular hypertrophy and any other electrical abnormalities. However, an ECG does not have sufficient sensitivity or specificity to act as a screening tool alone. ${ }^{5}$ All patients should have hematologic, serum electrolytes and thyroid function tests. Serological testing is important to detect underlying connective tissue disease (CTD), HIV, and hepatitis. Systemic sclerosis is the most common CTD to exclude because there is a high prevalence with PAH. Anti-centromere antibodies (ANAs) are typically positive in limited scleroderma. ${ }^{5}$

In $90 \%$ of patients with IPAH the chest radiograph is abnormal at the time of diagnosis. ${ }^{5}$ Findings include central pulmonary arterial dilation and "pruning" or loss of the peripheral blood vessels. Right atrial and right ventricular enlargement may be seen in more advanced cases. The chest radiograph also allows for evaluation of associated moderate-to-severe lung diseases (Group 3) or PH due to left sided heart disease (Group 2). ${ }^{5}$

Pulmonary function tests are obtained to identify underlying airway and parenchymal lung diseases. Patients with PAH tend to have decreased lung diffusion capacity for carbon monoxide (typically in the range of $40-80 \%$ of predicted) and mild to moderate reduction of lung volumes. ${ }^{5}$ The ventilation/perfusion lung scan should be performed in patients with $\mathrm{PH}$ to screen for potentially treatable chronic thromboembolic pulmonary hypertension (CTEPH). Surgical endarectomy for CTEPH can be curative for the associated PH. The ventilation/perfusion scan remains the screening method of choice for CTEPH because it has a higher sensitivity than the computed tomography pulmonary angiography (CTPA). ${ }^{11} \mathrm{~A}$ normal- or low-probability ventilation/perfusion scan effectively excludes CTEPH with a sensitivity of $90-100 \%$ and a specificity of $94-100 \%$. If the ventilation/perfusion scan shows small peripheral unmatched and nonsegmental defects in perfusion, a contrast-enhanced CT scan can be utilized to provide further information. ${ }^{5}$

Transthoracic echocardiography can be seen as the "gatekeeper" of diagnosis of PAH as it provides an estimation of right ventricular systolic pressure (RVSP) and information about the overall size and function of the heart. ${ }^{4}$ More specifically an estimation of pulmonary arterial pressure (PAP) is obtained based on peak velocity of the jet of tricuspid regurgitation. The estimation is based on the Bernoulli equation in which right ventricular systolic pressure $(\mathrm{RVSP})=\left(4 \times \mathrm{TRV}^{2}\right)+$ right atrial pressure. Right atrial pressure can be estimated based on the diameter and respiratory variation of the inferior vena cava, although often a fixed value of 5 or $10 \mathrm{~mm} \mathrm{Hg}$ is assumed. It is important to note that when tricuspid regurgitation is mild or severe, the estimated PAP may not be attainable or may be underestimated, respectively. ${ }^{12}$ An estimated RVSP greater than $40 \mathrm{~mm} \mathrm{Hg}$ generally warrants completion of a right heart catheterization, if there are no other explanations for unexplained dyspnea provided through the evaluation. ${ }^{4}$ 


\section{Treatment of PAH}

The goals of treatment are to improve symptoms and functional status along with improving morbidity and mortality. The prognosis and treatment approach for PAH is based on outcome predictors which include the NYHA functional class, exercise capacity through a 6 minute walk distance (6MWD), hemodynamics, imaging, and biomarkers. Therapeutic goals include: NYHA functional class I or II; 6 MWD 380 to 440 meters; cardiac index $\geq 2.5$ $\mathrm{L} / \mathrm{min} / \mathrm{m}^{2}$; normal right ventricular function on imaging; and normal brain natriuretic peptide (BNP) or N-terminal pro-BNP. ${ }^{13}$ Other predictors of decreased survival include: higher NYHA functional class, lower 6MWD, higher BNP or N-terminal BNP, higher creatinine levels, pericardial effusion, higher mean right atrial pressure, lower cardiac index and higher PVR. ${ }^{14}$ Attainment of these goals occurs through frequent follow up, lifestyle modification, conventional treatments, and disease-specific treatments.

\section{Lifestyle Modifications}

Although patients with PAH experience similar progressive exercise limitations as those patients with systolic heart failure and chronic obstructive pulmonary disease (COPD) where exercise is encouraged, exercise was initially discouraged for those with PAH due to concerns of clinical deterioration and adverse effects. Recently, several small studies have demonstrated that closely monitored and supervised exercise in the PAH population has positive effects in both improving exercise capacity and HRQOL. ${ }^{15}$ Referral to pulmonary rehabilitation which is commonly covered by insurance may be beneficial for patients to receive structured exercise in a supervised environment.

Adherence to a sodium-restricted diet ( $<2400 \mathrm{mg}$ per day) as well as fluid restriction should be encouraged as excess of either can worsen right heart failure. A nutritional consult may benefit the patient and/or family to discuss reading food labels; foods high in sodium that should be avoided; and how to prepare low sodium meals. Since respiratory infections are problematic for patients with $\mathrm{PAH},{ }^{5}$ immunizations against influenza and pneumococcal pneumonia are recommended. Patients should also avoid vasoconstricting sinus or cold preparations and anorexigens which could increase pulmonary artery pressures and PVR and exacerbate PAH symptoms. ${ }^{5}$

\section{Conventional treatments}

Diuretics are indicated to manage the volume overload resulting from right ventricular failure. As in left heart failure, serum electrolytes and renal function should be monitored closely when a patient is prescribed diuretics. Rapid, large-volume diuresis should be avoided except in the case of rapid onset cardiogenic pulmonary edema and/or worsening hypoxemia as the right ventricle is preload dependent. If the right heart is under filled hypotension may result. ${ }^{16}$ Commonly, loop-diuretic therapy is used resulting in potassium wasting. Potassium levels should be monitored and potassium supplements prescribed as needed to maintain normal levels.

Hypoxemia is a potent vasoconstrictor, hence most experts recommend oxygen supplementation to maintain an arterial saturation above $90 \%$. The underlying mechanism is 
not well understood but research suggests that decreased oxygen availability results in changes in reactive oxygen species production that causes calcium influx leading to vasoconstriction ${ }^{17}$ At present it is recommended that patients with PAH whose partial pressure of arterial oxygen $\left(\mathrm{PaO}_{2}\right)$ is consistently less than or equal to $55 \mathrm{~mm} \mathrm{Hg}$ or whose oxyhemoglobin saturation is less than or equal to $88 \%$ at rest, during sleep, or with ambulation should receive supplemental oxygen.${ }^{16}$ Patients need supplemental oxygen when traveling on commercial flights and/or when visiting areas at high altitude due to the possibility of pulmonary vasoconstriction from hypoxemia. ${ }^{5}$

Additionally, most experts recommend oral anticoagulants in patients with IPAH without contraindications and to consider warfarin therapy in patients with associated PAH with advanced disease, such as those patients receiving continuous IV therapy. ${ }^{16}$ However, uncertainty exists about the benefits of oral anticoagulants as there have been no randomized controlled trials to date examining the assumed benefits. A recent meta-analysis identified 9 cohort studies (2 prospective and 7 retrospective) that included a total of 1730 patients with PAH. The pooled results of these studies suggest a survival benefit. However, due to the over quality of the studies and the methodological limitations inherent in the analysis of observational studies a definitive conclusion about the benefit of anticoagulation in PAH patients is not possible. ${ }^{18}$ If patients are taking warfarin they need to have regular monitoring prothrombin time (PT) and international normalized ratio (INR). In addition, they need to be advised about the risk for increased bruising and bleeding along with food and/or drugs that may increase or decrease the action of anticoagulant therapy.

\section{Disease specific treatments}

High dose calcium channel blocker (CCB) therapy is indicated for patients who respond acutely to a vasodilator challenge during the right heart catheterization. ${ }^{5}$ An acute response is defined as a decrease in mean PAP of at least $10 \mathrm{mmHg}$ without a decrease in cardiac output. CCBs inhibit the influx of calcium into vascular cells leading to relaxation of smooth muscle cells and subsequent vasodilation. Although no randomized clinical trials have been performed to show the beneficial effects of CCBs in the treatment of PAH, several uncontrolled studies suggest that the long-term administration of high dose calcium antagonists dramatically improve survival in those patients who acutely respond to the vasodilation challenge during the RHC. ${ }^{19}$ Nifedipine is often initiated in those patients with heart rates less than 100 beats per minute, whereas Diltiazem is often the treatment of choice for those with heart rates greater than 100 beats per minute. Amlodipine is also acceptable for vasoresponsive patients. ${ }^{16}$ An important note, Verapamil is contraindicated for the treatment in patients with $\mathrm{PAH}$ due to the negative inotropic effects. ${ }^{20}$

Prostanoids - Prostacyclin is released from endothelial cells and causes vasodilation and inhibits platelet aggregation. It is theorized that since patients with PAH have dysfunctional endothelial cells they have a deficit in endogenous prostacyclin. As a result exogenous administration is provided through continuous intravenous or subcutaneous, intermittent inhaled, or most recently through an oral formulation (Table 2). 
Oral treprostinil extended release was approved in December 2013 for the treatment of PAH in patients to improve exercise capacity. The primary efficacy study, Oral Treprostinil as a Monotherapy for Treatment of PAH (FREEDOM-M), demonstrated that patients receiving treprostinil twice daily (BID) improved their median 6MWD by 23 meters $(\mathrm{p}=0.013)$ as compared to patients receiving the placebo. ${ }^{21}$ Two other Phase 3 studies (FREEDOM-C and FREEDOM-C ${ }^{2}$ ) looked at combining treprostinil with another approved PAH therapy but did not demonstrate a benefit in exercise with a median 6MWD at week 16 (11 meters $[\mathrm{p}=0.072]$ and 10 meters [ $\mathrm{p}=0.089]$, respectively). ${ }^{22}$ The most common side effects reported in the clinical trials were headache, nausea, and diarrhea.

Selexipag is an orally available, selective prostacyclin IP receptor agonist. It is rapidly hydrolyzed in the hepatic microsomes to an active metabolite. Both selexipag and its active metabolite have a higher affinity for the human IP receptor than for any other prostanoid receptor. Although selexipag and its active metabolite have actions similar to endogenous prostacyclin they are chemically distinct from prostacyclin with a different pharmacology. ${ }^{23}$ Selexipag is currently being evaluated in the Phase III GRIPHON trial, a multicenter, double blind, placebo controlled trial that is evaluating the efficacy and safety of oral selexipag in patients with PAH. In February of 2014 the trial reached the total number of primary endpoint events required to close the study. Results of this trial are pending.

Endothelin receptor antagonists (ERA) - Endothelin-1 is a vasoconstrictor that may contribute to the development of PAH. ${ }^{4}$ Blocking endothelin may prevent vasoconstriction and remodeling of the vasculature. Bostentan, ambrisentan, and most recently macitentan are all ERAs (Table 3). Macitentan is a novel dual endothelin receptor antagonist with sustained receptor binding properties. It was developed through modification of the structure of bosentan with an aim of improving drug efficacy. As with other ERAs it carries a Boxed Warning stating that the drug should not be used in pregnant women due to harmful effects on the developing fetus. Like other drugs in this class, female patients are only able to receive the drug through the Risk Evaluation and Mitigation Strategy (REMS), which is a program mandated by the Food and Drug Administration (FDA) to manage serious risks associated with the drug. Patients need to have monthly liver function tests and quarterly complete blood counts (CBC) while taking bosentan. Monthly pregnancy tests must be performed with all ERAs and periodic $\mathrm{CBC}$ with ambrisentan and macitentan. The most frequent adverse effects associated with the drug are nasopharyngitis, headache, and anemia. $^{24}$

Nitric oxide pathway - the pulmonary vasculature is dilated by nitric oxide via cyclic guanosine monophosphate (cGMP). Phosphodiesterase type 5 is an enzyme that metabolizes cGMP. Phosphodiesterase type 5 (PDE5) inhibitors block cGMP which in turn promotes vasodilation and inhibits proliferation of the smooth muscle in the pulmonary vasculature. ${ }^{25}$ The two approved PDE5s are sildenafil and tadalafil (Table 4).

Riociguat also works in the nitric oxide pathway. It is a first-in-class soluable guanylate cyclase (sGC) stimulator. The drug directly stimulates sGC in a nitric oxide independent manner, thereby increasing the sensitivity of sGC to nitric oxide. This leads to an increase in cGMP which is a key signaling molecule involved in regulating vascular tone, proliferation, 
fibrosis and inflammation. It is approved for adult patients with inoperable or CTEPH or PAH. ${ }^{26}$ Due to its teratogenicity, female patients must be on two forms of birth control and enroll in the REMS program and have monthly pregnancy tests. Additionally, either heartlung or double lung transplantation is an option for patients with $\mathrm{PAH}$ who are not improving with optimal medical treatment. ${ }^{5}$

\section{The Role of the Nurse Practitioner}

The NP plays a crucial role in the management of the PAH patient, acting as link between the patient, staff, and physician. During the diagnostic process, the NP helps to coordinate the indicated testing. Once the diagnosis is made and the initial treatment is started, the NP provides guidance on dose titration as well as the need for additional therapy. Further the NP provides care related to medication adherence, nutrition, exercise, mental health, and broader life concerns such as discussions regarding palliative care.

The organization of support groups, which provide patients the opportunity to interact each other is often led by the NP. Additionally, the NP advocates for patients to ensure that they receive the medications needed for optimal management as well as additional support services as needed. The education of nursing staff responsible for the care of PAH is often lead by the NP. This education may include, but is not limited to education on the disease state, drugs utilized for treatment and the pumps used for administration.

Given the disease burden and alteration in HRQOL in patients with PAH, patients have understandable concerns about management of symptoms, utilization of medications, and moreover how to live with $\mathrm{PAH}{ }^{27}$ NPs play a crucial role in this transition. Further, inclusion of the family is imperative. Concerns of caregivers include fear and frustration with dealing with their loved one's diagnosis. ${ }^{28}$ Caregivers may need someone to speak to or a place to go to discuss their concerns. The NP can either be available to answer their questions or refer them to other resources such as support groups both in person or online venues. The Pulmonary Hypertension Association provides an excellent source of information along with an online Discussion Board for patients and family to post comments and/or ask questions http://phassociation.org/.

Lastly, incorporation of palliative care is essential as it is a chronic, life-limiting diseases. ${ }^{29}$ Patients with PAH suffer multiple symptoms that diminish their HRQOL ${ }^{2}$ and utilization of palliative care will help to establish goals of care, management of symptoms, and as the disease progresses transition to hospice care if needed. The NP caring for patients with PAH are in a pivotal position for recommending and advocating palliative care for patients.

\section{Conclusions}

PAH is a progressive disease that currently has no cure. Since patients present with symptoms such as dyspnea, fatigue, and chest pain that mimic other cardiac and/or respiratory diseases diagnosis is often delayed. An extensive medical work-up is required to rule out the presence of other diseases and a right heart catheterization provides a definitive diagnosis. PAH specific therapies help to decrease associated symptoms and slow the progression of the disease. The NP is integral in the care of patients and families with PAH. 


\section{Acknowledgments}

Funding: This work was partially supported by the National Institutes of Health grant K23 NR014885.

\section{References}

1. Simonneau G, Gatzoulis MA, Adatia I, et al. Updated Clinical Classification of Pulmonary Hypertension. Journal of the American College of Cardiology. 2013; 62(25_S)

2. Matura L, McDonough A, Carroll D. Cluster analysis of symptoms in pulmonary arterial hypertension: a pilot study. European Journal of Cardiovascular Nursing. Mar 1; 2012 11(1):51-61. 2012. [PubMed: 22357779]

3. Benza RL, Miller DP, Gomberg-Maitland M, et al. Predicting Survival in Pulmonary Arterial Hypertension: Insights From the Registry to Evaluate Early and Long-Term Pulmonary Arterial Hypertension Disease Management (REVEAL). Circulation. Jul 13; 2010 122(2):164-172. 2010. [PubMed: 20585012]

4. McLaughlin VV, Badesch DB, Delcroix M, et al. End Points and Clinical Trial Design in Pulmonary Arterial Hypertension. Journal of the American College of Cardiology. 2009; 54(1, Supplement):S97-S107. [PubMed: 19555863]

5. Galiè N, Hoeper MM, Humbert M, et al. Guidelines for the diagnosis and treatment of pulmonary hypertension. European Heart Journal. Oct 1; 2009 30(20):2493-2537. 2009. [PubMed: 19713419]

6. McGoon MD, Benza RL, Escribano-Subias P, et al. Pulmonary Arterial Hypertension Epidemiology and Registries. Journal of the American College of Cardiology. 2013; 62(25_S)

7. Budhiraja R, Tuder RM, Hassoun PM. Endothelial Dysfunction in Pulmonary Hypertension. Circulation. Jan 20; 2004 109(2):159-165. 2004. [PubMed: 14734504]

8. Tuder RM, Archer SL, Dorfm ̃̃ pulmonary hypertension. Journal of the American College of Cardiology. 2013; 62(25_S)

9. Armstrong I, Rochnia N, Harries C, Bundock S, Yorke J. The trajectory to diagnosis with pulmonary arterial hypertension: a qualitative study. BMJ open. 2012; 2(2)

10. The Criteria Committee of the NewYork Heart Association. Nomenclature and Criteria for Diagnosis of Diseases of the Heart and Great Vessels. 9th. Little, Brown \& Co; Boston: 1994.

11. Tunariu N, Gibbs SJ, Win Z, et al. Ventilation-perfusion scintigraphy is more sensitive than multidetector CTPA in detecting chronic thromboembolic pulmonary disease as a treatable cause of pulmonary hypertension. Journal of Nuclear Medicine. 2007; 48(5):680-684. [PubMed: 17475953]

12. Vachiéry J-L, Gaine S. Challenges in the diagnosis and treatment of pulmonary arterial hypertension. European respiratory review. 2012; 21(126):313-320. [PubMed: 23204119]

13. McLaughlin V. Managing pulmonary arterial hypertension and optimizing treatment options: prognosis of pulmonary artery hypertension. The American Journal of Cardiology. 2013; 111(8): 10C-15C.

14. McGoon M, Humbert M. Pulmonary arterial hypertension; epidemiology and registries. Advances in Pulmonary Hypertension. 2014; 33(2):23-26.

15. Zafrir B. Exercise Training and Rehabilitation in Pulmonary Arterial Hypertension: RATIONALE AND CURRENT DATA EVALUATION. Journal of cardiopulmonary rehabilitation and prevention. 2013; 33(5):263-273. [PubMed: 23962982]

16. Sauler M, Fares WH, Trow TK. Standard Nonspecific Therapies in the Management of Pulmonary Arterial Hypertension. Clinics in chest medicine. 2013; 34(4):799-810. [PubMed: 24267305]

17. Weissmann N, Tadić A, Hänze J, et al. Hypoxic vasoconstriction in intact lungs: a role for NADPH oxidase-derived H2O2? American Journal of Physiology-Lung Cellular and Molecular Physiology. 2000; 279(4):L683-L690. [PubMed: 11000128]

18. Caldeira D, Loureiro MJ, Costa J, Pinto FJ, Ferreira JJ. Oral anticoagulation for pulmonary arterial hypertension: systematic review and meta-analysis. Canadian Journal of Cardiology. 2014

19. Chaumais, M-C.; Macari, EA.; Sitbon, O. Pharmacotherapy of Pulmonary Hypertension. Springer; 2013. Calcium-Channel Blockers in Pulmonary Arterial Hypertension; p. 161-175. 
20. Moores L. Pulmonary Vascular Diseases ACCP Pulmonary Medicine Review Board2012. Accessed 01/09/2015.

21. Jing Z-C, Parikh K, Pulido T, et al. Efficacy and safety of oral treprostinil monotherapy for the treatment of pulmonary arterial hypertension: a randomized controlled trial. Circulation. 2013; 112:124388. CIRCULATIONAHA.

22. Tapson VF, Jing Z-C, Xu K-F, et al. Oral Treprostinil for the Treatment of Pulmonary Arterial Hypertension in Patients Receiving Background Endothelin Receptor Antagonist and Phosphodiesterase Type 5 Inhibitor Therapy (The FREEDOM-C2 Study) Treprostinil for Pulmonary Arterial HypertensionA Randomized Controlled Trial. CHEST Journal. 2013; 144(3): 952-958.

23. Simonneau G, Torbicki A, Hoeper MM, et al. Selexipag: an oral, selective prostacyclin receptor agonist for the treatment of pulmonary arterial hypertension. European Respiratory Journal. 2012; 40(4):874-880. [PubMed: 22362844]

24. Patel T, McKeage K. Macitentan: First Global Approval. Drugs. 2014; 74(1):127-133. [PubMed: 24297706]

25. Galiè N, Ghofrani HA, Torbicki A, et al. Sildenafil citrate therapy for pulmonary arterial hypertension. New England Journal of Medicine. 2005; 353(20):2148-2157. [PubMed: 16291984]

26. Conole D, Scott LJ. Riociguat: First global approval. Drugs. 2013; 73(17):1967-1975. [PubMed: 24218053]

27. Matura LA, McDonough A, Aglietti LM, Herzog JL, Gallant KA. A Virtual Community: Concerns of Patients With Pulmonary Hypertension. Clinical Nursing Research. May 1; 2013 22(2):155171. 2013. [PubMed: 23093554]

28. Lichenstein S, McDonough A, Matura L. Cyber Support: Describing Concerns of Caregivers of People With Pulmonary Hypertension. Computers Informatics Nursing. 2013; 31(12):581-588.

29. Freysteinson WM. Complex, Chronic, and End-of-Life Care: The Interface Between Critical Care and Palliative Care. Critical care nursing quarterly. 2010; 33(3):265-272. [PubMed: 20551741] 


\section{Highlights}

- Pulmonary arterial hypertension is a chronic, debilitating disease that leads to right heart failure and premature death.

- The diagnosis of PAH is one of exclusion.

- PAH-specific treatments include: prostanoids, enothelin receptor antagonists and phosphodiesterase-5 inhibmitors. 
Table 1

Updated Classification of Pulmonary Hypertension*

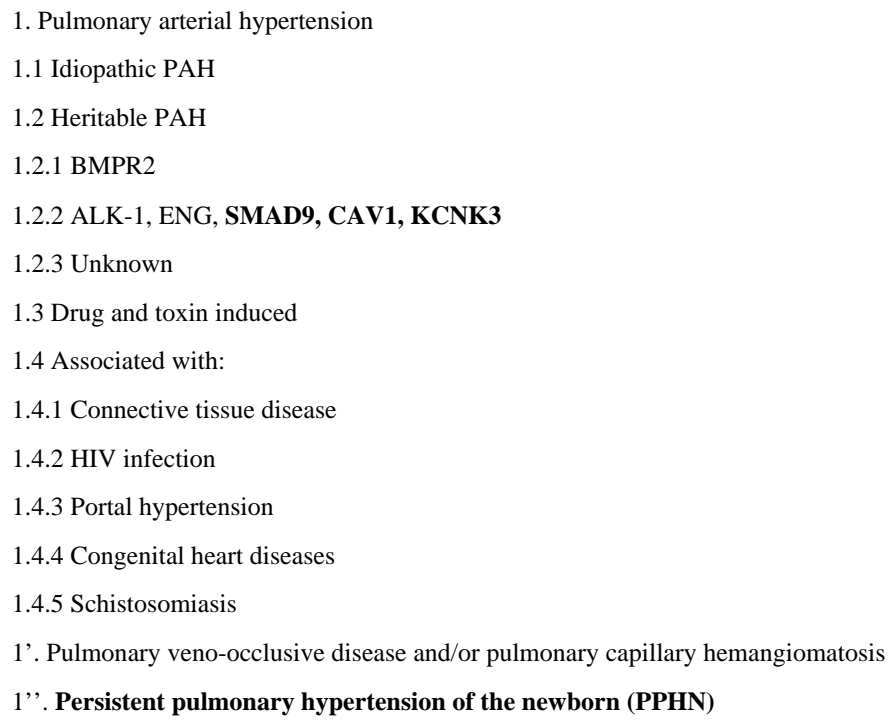

2. Pulmonary hypertension due to left heart disease

2.1 Left ventricular systolic dysfunction

2.2 Left ventricular diastolic dysfunction

2.3 Valvular disease

2.4 Congenital/acquired left heart inflow/outflow tract obstruction and congenital cardiomyopathies

3. Pulmonary hypertension due to lung diseases and/or hypoxia

3.1 Chronic obstructive pulmonary disease

3.2 Interstitial lung disease

3.3 Other pulmonary diseases with mixed restrictive and obstructive pattern

3.4 Sleep-disordered breathing

3.5 Alveolar hypoventilation disorders

3.6 Chronic exposure to high altitude

3.7 Developmental lung diseases

4. Chronic thromboembolic pulmonary hypertension (CTEPH)

5. Pulmonary hypertension with unclear multifactorial mechanisms

5.1 Hematologic disorders: chronic hemolytic anemia, myeloproliferative disorders, splenectomy

5.2 Systemic disorders: sarcoidosis, pulmonary histiocytosis, lymphangioleiomyomatosis

5.3Metabolic disorders: glycogen storage disease, Gaucher disease, thyroid disorders

5.4 Others: tumoral obstruction, fibrosing mediastinitis, chronic renal failure,segmental PH

BMPR2 - bone morphogenetic protein receptor type II; Alk-I - activin receptor like kinase 1; Eng - endoglin; CAV-1 - caveolin I

5th WSPH Nice 2013. Main modifications to the previous Dana Point classification are in bold.

J Nurse Pract. Author manuscript; available in PMC 2016 May 01. 
Table 2

Prostanoid Therapy

\begin{tabular}{|c|c|c|c|}
\hline \multicolumn{4}{|c|}{ Continuous Infusion Prostanoids } \\
\hline Medication & Dosing & Mechanism of Action & $\begin{array}{l}\text { Drug-Drug } \\
\text { Interaction }\end{array}$ \\
\hline Epoprostenol & $\begin{array}{l}\text { Start at } 2 \mathrm{ng} / \mathrm{kg} / \text { minute } \\
\text { IV and may increase } \\
\text { by } 2 \mathrm{ng} / \mathrm{kg} / \text { minute to } \\
\text { desired clinical effects. }\end{array}$ & $\begin{array}{l}\text { Direct vasodilation of } \\
\text { pulmonary and systemic } \\
\text { arterial vascular beds and } \\
\text { inhibition of platelet } \\
\text { aggregation }\end{array}$ & $\begin{array}{l}\text { Other } \\
\text { vasodilators }\end{array}$ \\
\hline Treprostinil & $\begin{array}{l}\text { Start at } 1.25 \\
\mathrm{ng} / \mathrm{kg} / \mathrm{minute} \mathrm{SC} / \mathrm{IV} \\
\text { and increase by } 1.25 \\
\mathrm{ng} / \mathrm{kg} / \mathrm{min} \text { as clinical } \\
\text { indicated }\end{array}$ & $\begin{array}{l}\text { Direct vasodilation of } \\
\text { pulmonary and systemic } \\
\text { arterial vascular beds and } \\
\text { inhibition of platelet } \\
\text { aggregation }\end{array}$ & $\begin{array}{l}\text { Other } \\
\text { vasodilators }\end{array}$ \\
\hline \multicolumn{4}{|c|}{ Inhaled Prostanoids } \\
\hline Iloprost & $\begin{array}{l}2.5-5 \text { mcg NEB 6- } \\
9 x / \text { day }\end{array}$ & $\begin{array}{l}\text { Exact mechanism is not } \\
\text { known; dilates systemic and } \\
\text { pulmonary arterial vessels }\end{array}$ & $\begin{array}{l}\text { May increase the } \\
\text { effects of } \\
\text { vasodilators and } \\
\text { antihypertensive } \\
\text { agents; may } \\
\text { increase effects } \\
\text { of anticoagulants } \\
\text { or platelet } \\
\text { inhibitors }\end{array}$ \\
\hline $\begin{array}{l}\text { Inhaled } \\
\text { Treprostinil }\end{array}$ & $\begin{array}{l}\text { Each breath }=6 \mathrm{mcg} \text {. } \\
\text { Initiate at } 3 \text { breaths ( } 18 \\
\text { mcg) QID and increase } \\
\text { to } 9 \text { breaths ( } 54 \mathrm{mcg} \text { ) } \\
\text { four times daily }\end{array}$ & $\begin{array}{l}\text { Prostacyclin analogue. Direct } \\
\text { vasodilation of pulmonary } \\
\text { and systemic arterial vascular } \\
\text { beds and inhibitions of } \\
\text { platelets }\end{array}$ & $\begin{array}{l}\text { May increase the } \\
\text { effects of } \\
\text { vasodilators and } \\
\text { antihypertensive } \\
\text { agents; may } \\
\text { increase effects } \\
\text { of anticoagulants } \\
\text { or platelet } \\
\text { inhibitors }\end{array}$ \\
\hline \multicolumn{4}{|c|}{ Oral Prostanoids } \\
\hline $\begin{array}{l}\text { Oral } \\
\text { Treprostinil }\end{array}$ & $\begin{array}{l}\text { Starting dose: } 0.25 \mathrm{mg} \\
\text { BID. Titrate by } 0.25 \mathrm{or} \\
0.5 \mathrm{mg} \text { BID or } 0.125 \mathrm{mg} \\
\text { TID, no more than } \\
\text { every } 3 \text { to } 4 \text { days as } \\
\text { tolerated. Maximum } \\
\text { dose determined by } \\
\text { tolerability. Extended } \\
\text { release tablets available } \\
\text { in: } 0.125 \mathrm{mg}, 0.25 \mathrm{mg}, 1 \\
\mathrm{mg} \text { and } 2.5 \mathrm{mg}\end{array}$ & $\begin{array}{l}\text { Prostacyclin analogue. Direct } \\
\text { vasodilation of pulmonary } \\
\text { and systemic arterial vascular } \\
\text { beds and inhibitions of } \\
\text { platelets }\end{array}$ & $\begin{array}{l}\text { Blood pressure } \\
\text { lowering } \\
\text { medications (e.g. } \\
\text { diuretics, } \\
\text { antihypertensives, } \\
\text { or vasodilators. } \\
\text { When co- } \\
\text { administration } \\
\text { with strong } \\
\text { CYP2C8 } \\
\text { inhibitors initial } \\
\text { dose is } 0.125 \mathrm{mg} \\
\text { BID with } 0.125 \\
\text { mg BID dose } \\
\text { increments every } \\
3 \text { to } 4 \text { days. }\end{array}$ \\
\hline Selexipag & $\begin{array}{l}\text { Pending FDA Approval } \\
\text { Starting trial dose: } 200 \\
\mu \mathrm{g} \text { BID to a max } \\
\text { tolerated dose }(800 \mu g \\
\text { BID) }\end{array}$ & $\begin{array}{l}\text { Selective non-prostanoid IP } \\
\text { receptor agonist. Both } \\
\text { Selexipag and its metabolite } \\
\text { are highly selective for the IP } \\
\text { receptor compared to other } \\
\text { prostanoid receptors. }\end{array}$ & $\begin{array}{l}\text { Pending FDA } \\
\text { approval. } \\
\text { Information not } \\
\text { yet available. }\end{array}$ \\
\hline
\end{tabular}

$\mathrm{BID}=$ twice daily; FDA= Food and Drug Administration; IV=intravenous; $\mathrm{SC}=$ subcutaneous; $\mathrm{TID}=$ three times daily 
Table 3

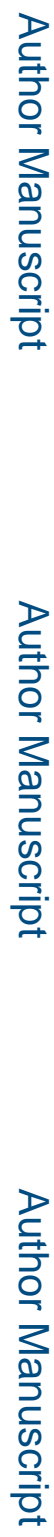

Endothelin Receptor Antagonists

\begin{tabular}{|l|l|l|l|}
\hline Medication & Dosing & Mechanism of Action & $\begin{array}{l}\text { Drug-Drug } \\
\text { Interaction }\end{array}$ \\
\hline Bosentan & $62.5 \rightarrow 125 \mathrm{mg}$ PO BID & $\begin{array}{l}\text { Binds to endothelin } \\
\text { receptors, blocking } \\
\text { vasoconstrictive effects of } \\
\text { endothelin-1 }\end{array}$ & $\begin{array}{l}\text { Glyburide } \\
\text { Protease } \\
\text { Inhibitors PDE5- } \\
\text { inhibitors } \\
\text { Hormonal Agents } \\
\text { Calcineurin } \\
\text { Inhibitors } \\
\text { Ketoconazole } \\
\text { Rifampin }\end{array}$ \\
\hline Ambrisentan & $5 \mathrm{mg}$ or $10 \mathrm{mg}$ PO daily & $\begin{array}{l}\text { Selectively binds to } \\
\text { endothelin type-A receptors, } \\
\text { blocking vasoconstrictive } \\
\text { effects of endothelin-1 }\end{array}$ & Cyclosporine \\
\hline Macitentan & $10 \mathrm{mg}$ PO daily & $\begin{array}{l}\text { Binds to endothelin } \\
\text { receptors, blocking } \\
\text { vasoconstrictive effects of } \\
\text { endothelin-1 }\end{array}$ & $\begin{array}{l}\text { Ketoconazole } \\
\text { Rifampin } \\
\text { (limited } \\
\text { information } \\
\text { available) }\end{array}$ \\
\hline
\end{tabular}

$\mathrm{BID}=$ twice daily 
Table 4

Phosphodiesterase-5 (PDE-5) Inhibitors

\begin{tabular}{|l|l|l|l|}
\hline Medication & Dosing & Mechanism of Action & $\begin{array}{l}\text { Drug-Drug } \\
\text { Interaction }\end{array}$ \\
\hline Sildenafil & $\begin{array}{l}\text { 20 mg TID PO } \\
2.5 \mathrm{mg} \text { or } 10 \mathrm{mg} \text { IV TID } \\
\text { (later equivalent to 20 } \\
\mathrm{mg} \text { PO) }\end{array}$ & $\begin{array}{l}\text { Enhances the effects of nitric } \\
\text { oxide }\end{array}$ & $\begin{array}{l}\text { Nitrates } \\
\text { Alpha-blocker } \\
\text { Amlodipine } \\
\text { Ritonavir or other } \\
\text { potent CYP3A } \\
\text { inhibitors }\end{array}$ \\
\hline Tadalafil & $40 \mathrm{mg}$ PO daily & $\begin{array}{l}\text { Enhances the effects of nitric } \\
\text { oxide }\end{array}$ & $\begin{array}{l}\text { Nitrates } \\
\text { Alpha-Blocker } \\
\text { Antihypertensives } \\
\text { Alcohol }\end{array}$ \\
\hline Riociguat & $\begin{array}{l}\text { Initiate } 1 \mathrm{mg} \text { PO TID, if } \\
\text { not tolerated due to } \\
\text { hypotensive } 0.5 \mathrm{mg} \\
\text { TID. Titrate to } 2.5 \mathrm{mg} \\
\text { TID }\end{array}$ & $\begin{array}{l}\text { Stimulates binding of soluble } \\
\text { guanylate cyclase to nitric } \\
\text { oxide, increasing cGMP } \\
\text { production/vasodilation }\end{array}$ & $\begin{array}{l}\text { Nitrates } \\
\text { PDE Inhibitors }\end{array}$ \\
\hline
\end{tabular}

$\mathrm{TID}=$ three times daily 